

\title{
Desire SATISfaCtionism and THE Problem OF IRRELEVANT DESIRES
}

BY MARK LUKAS

Journal OF ETHICs \& SOCIAL PHILOSOPHY

VOL. 4, NO. 2 | JUNE 2010 URL: WWW.JESP.ORG COPYRIGHT (C) MARK LUKAS 2010 


\section{Desire Satisfactionism and the Problem of Irrelevant Desires Mark Lukas}

$\mathrm{D}$ ESIRE SATISFACTIONISM ABOUT WELFARE comes in two main varieties: unrestricted and restricted. ${ }^{1}$ Both varieties entail that a person's well-being is determined entirely by the satisfactions and frustrations of his desires. But while the restricted theories count only some of a person's desires as relevant to his well-being - perhaps just the fully informed desires or those that would survive cognitive psychotherapy - the unrestricted theory counts all of his desires as relevant. On this theory, it does not matter what a person wants or why he wants it; so long as he gets what he wants, his life goes well. Because the unrestricted theory counts all desires as relevant, it is vulnerable to a wide variety of counterexamples involving desires that seem obviously irrelevant. Derek Parfit offers a wellknown example:

Suppose I meet a stranger who has what is believed to be a fatal disease. My sympathy is aroused, and I strongly want this stranger to be cured. We never meet again. Later, unknown to me, this stranger is cured. On the Unrestricted Desire...Theory, this event is good for me, and makes my life go better. This is not plausible. We should reject this theory. ${ }^{2}$

Similar examples have been offered by Thomas Scanlon, James Griffin, Shelly Kagan and others. ${ }^{3}$ These examples all feature desires whose objects seem well beyond the bounds of what most people take to be relevant to welfare. Consider a few of my own desires, borrowed from the literature: I am a nice guy and so I want people in the $29^{\text {th }}$ century to flourish. I am a fan of prime numbers and so I want the total number of atoms in the universe to be prime. I am interested in cosmic affairs and so I have a desire about the chemical composition of some distant star. I am a weirdo and so I want it to be the case that Napoleon's favorite color was blue. Are any of these desires relevant to my well-being? Would their satisfaction be good for me? Unrestricted desire satisfactionism entails that it would be good for me if they were satisfied. But obviously it would not be; that is absurd. Or so say the objectors. This is the Irrelevant-Desires Problem.

In what follows, I defend a simple unrestricted form of desire satisfactionism from the Irrelevant-Desires Problem. I begin by sketching the theory and outlining some of its more attractive features. I then formulate the Irrelevant-Desires Problem and reject a few rationales for its key premise. Then I consider and reject a few flawed responses to the Irrelevant-Desires Problem. Lastly, I offer an obvious but widely overlooked response to the problem: I bite the bullet. My overall goal is modest; I want to dissuade those

1 Throughout, I use "well-being" and "welfare" interchangeably.

2 Parfit (1984: p. 494).

3 Scanlon (1993: pp. 186-87), Scanlon (1996: p. 100), Scanlon (1998: pp. 120-21), Griffin

(1986: pp. 16-7), Kagan (1998: p. 37), Sumner (1996: p. 132), Murphy (1999: p. 269). 
sympathetic to a desire-based approach to welfare from rejecting unrestricted desire satisfactionism simply because of the Irrelevant-Desires Problem.

\section{Formulating a Simple Unrestricted Desire Satisfactionism}

The theory I aim to defend, Simple Unrestricted Desire Satisfactionism (SUDS), is a theory about what makes a life intrinsically good for the person who lives it. ${ }^{\text {It }}$ is not about what makes a person's life good in some other way. So it is not a theory about what makes a person's life instrumentally good or morally good or aesthetically good or intrinsically good simpliciter. It is consistent with SUDS, then, that a person could live a life that is intrinsically very good for him and yet a complete disaster for the world. Such a person might, for instance, enjoy a very high level of well-being owing to the fact that he has successfully managed to enslave everyone on earth for the sole purpose of enhancing his own welfare. His life might be harmful to others, full of morally reprehensible behavior, ugly, and it might diminish the intrinsic value of the world in which it occurs; but it might nevertheless be a very good life for him.

The basic idea behind SUDS is that well-being consists in achieving an optimal overall match between the way things are and the way we want them to be, whatever we may happen to want. On this view, to advance well-being is to reconcile our actual desires with the world by getting what we actually want or wanting what we actually get. We can think of SUDS as the conjunction of the following three theses:

T1: Every desire satisfaction is intrinsically good for its subject; every desire frustration is intrinsically bad for its subject. (Satisfactions are of this form: $\mathrm{S}$ desires that $\mathrm{p} \& \mathrm{p}$; frustrations, this form: $\mathrm{S}$ desires that $\mathrm{p} \& \sim \mathrm{p}$.)

T2: The intrinsic value of a desire satisfaction for its subject $=$ the intensity of the desire satisfied; the intrinsic value of a desire frustration for its subject $=-$ (the intensity of the desire frustrated).

T3: The intrinsic value of a life (or life-part) for the one who lives it $=$ the sum of the intrinsic values of all the desire satisfactions and frustrations it contains.

${ }_{4}$ Throughout, I write as if welfare value is a species of intrinsic value. Thus I write as if a thing could be intrinsically good or bad for a person. And I say that desire satisfactions are intrinsically good for people and frustrations are intrinsically bad for people. For present purposes, aside from my criticism of Kagan, not much hinges on this choice of terminology. The theory I defend here could just as easily have been cast in terms of, say, prudential value or non-instrumental value. Accordingly, the reader should feel free to substitute phrases such as "intrinsically good for" with those such as "prudentially good for" or "non-instrumentally good for." Whatever we call it, I trust that the kind of value I am concerned with here is familiar to the reader and is presented in a way that is sufficiently clear so as to avoid confusing it with some other kind of value, say, instrumental or moral value. 
There are several things to note about SUDS. First, satisfaction and frustration do not require any feelings of satisfaction or frustration, nor do they require any belief, knowledge or any other kind of awareness on the part of the one who desires that his desire is satisfied or frustrated. They require merely that what he wants is or is not the case. Thus my current desire that people in the $29^{\text {th }}$ century flourish is now satisfied or frustrated, though I know not which and am presently agnostic about the matter. It is satisfied provided that people in the $29^{\text {th }}$ century flourish; frustrated otherwise. Now of course if I manage to live a very long time, or become a time traveler like Dr. Who, then I might come to know or believe that my desire has been satisfied or frustrated, but as it stands I have no idea.

Second, evaluating a person's well-being is a matter of evaluating how intrinsically valuable his life is for him or how intrinsically valuable some part of his life is for him. Accordingly, I take it that the main task of giving an account of well-being comes down to specifying how we ought to assign values to a life and its parts. This raises a question about which parts of a life we should be concerned with. Certainly extended segments of a life should be of concern. Our account should tell us how, for example, to assign a value to, say, the first half of a person's life or to the last half of it. And of course it should tell us how to assign a value to the whole composed of these two parts. But what about very small parts of a person's life? Do we need to be concerned with assigning values to specific moments in a life? Indeed, does it even make sense to wonder about how well someone is doing at just some one instant in time? Or are assessments of well-being best thought of as assessments of how valuable temporally extended segments of a life are? Although I am not sure how to answer these questions, it does seem reasonably clear to me how we might evaluate well-being both at a time and over an extended period of time in terms of satisfactions and frustrations of desires.

According to SUDS, if we are interested in figuring how intrinsically valuable some particular moment of a person's life is for him, we first identify all the desires he has at that moment; we then note their intensities and whether they are satisfied or frustrated; and finally we sum the relevant values. The result will be a number that tells us his level of well-being at that one moment; greater numbers represent higher levels of well-being and smaller numbers lower levels. In a similar way, we could assign values to temporally extended parts of a person's life or indeed his entire life. We first identify all the desires he has during the period of life in question, note their intensities and whether they are satisfied or frustrated, assign values as determined by the relevant intensities, and then sum all the values. What we end up with is a number representing the value of the period of time in question; again, greater numbers represent more valuable periods in the life and smaller numbers represent less valuable periods.

Another thing to note about SUDS is that it assigns value to wanting and getting, not merely getting. In other words, if the object of a person's desire occurs, it is not the occurrence of this object that is intrinsically good 
for the person; rather, it is the occurrence of the state of affairs that consists in his desiring it and its occurrence. Thus SUDS does not entail, for example, that the stranger's cure would be intrinsically good for Parfit. The good thing according to SUDS would be the cure together with Parfit's wanting it. So, according to SUDS, the basic building blocks of well-being are states of affairs that supervene in part on mental states (desires) and in part on the state of the world (objects of desire)..$^{5}$

Perhaps the most important thing to note about SUDS is that it places no restrictions on which desires are relevant to well-being. It says that all desire satisfactions are good for us and all frustrations are bad, no matter what the relevant desires happen to be about. This fact about SUDS opens it to a variety of objections that are not the topic of this paper. Some of these objections play on the fact that our desires are often based on false beliefs, misinformation, mental illness or sloppy thinking. As a result we frequently want things that are bad for us. I might want to drink from the stream because I mistakenly believe that it is not poisonous. How could it be good for me to get what I want in such cases? Versions of this kind of objection have been discussed by many philosophers. ${ }^{6}$ Some objections are based on the idea that desire-based theories like SUDS rule out the possibility of self-sacrifice. ${ }^{7}$ Derek Parfit suggests that if such theories are true, we might all be better off becoming drug addicts or getting lobotomies. ${ }^{8}$ Richard Brandt suggests that such theories are incoherent. ${ }^{9}$ And Ben Bradley objects to theories relevantly similar to SUDS on the grounds that they are paradoxical. ${ }^{10}$ I mention these objections to set them aside and to focus the reader's attention on the problem at hand. I want to focus on the objection that at least some desires are irrelevant to well-being - that sometimes getting what we want, or failing to get it, makes no difference to how well our lives go.

\section{Motivation for SUDS}

Given the vast array of difficulties faced by desire-based theories like SUDS, one might wonder why anyone would find such theories attractive at all. Perhaps the primary appeal of a theory like SUDS is the ease with which it handles various well-known problems that beset so-called mental state theories of well-being. Such theories entail that well-being supervenes on mental

${ }^{5}$ Of course many of our desires are themselves about mental-states - my desire to be happy, for example.

6 See Schwartz (1982: pp. 195-96), Griffin (1986: p. 10), Sen (1993: p. 79), Sobel (1994: p. 788), Noggle (1998: pp. 304-10), Carson (2000: p. 72).

7 See Schwartz (1982: pp. 199-200), Overvold (1982: pp. 186-94), Brandt (1996: p. 287), Kraut (1997: pp. 165-66), Hooker (1993: pp. 205-13), Adams (1999: pp. 87-91), Griffin (2002: p. 316).

8 Parfit (1984: p. 498).

${ }_{9}$ Brandt (1982).

${ }_{10}$ Bradley (2007). 
states so that any difference in well-being entails a difference in mental states. But, as a number of philosophers and ordinary folk have suggested, there seem to be cases in which one's well-being is affected by things that ultimately make no difference whatsoever to one's mental states. Examples of such cases crop up frequently in the literature surrounding the possibility of posthumous harm and benefit. Aristotle famously suggests that such cases exist. More recently, Thomas Nagel says things to suggest that it would be good for me if the executor of my will abides by my wishes once I am gone. ${ }^{11}$ And surely if the executor does this, it would not make a bit of difference in any of my mental states; once I am dead, I have no more mental states.

Somewhat less controversial examples involve what goes on behind our backs while we are still alive. Hare, Nagel and others have given us examples of this sort. In his book Harm to Others, Joel Feinberg persuasively suggests that, indeed, what I do not know can hurt me:

If someone spreads a libelous description of me among a group whose good opinion I covet and cherish, altogether without my knowledge, I have been injured in virtue of the harm done my interest in a good reputation, even though I never learn what has happened. That is because I have an interest, so I believe, in having a good reputation as such, in addition to my interest in avoiding hurt feelings, embarrassment, and economic injury. And that interest can be seriously harmed without my ever learning of it. ${ }^{12}$

Consider another example from Feinberg. Judy devotes thirty years of her life to the furtherance of certain ideals and ambitions in the form of one vast undertaking. She founds an institution dedicated to these ends and works single-mindedly for its advancement, both for the sake of the social good she believes it to promote, and for the sake of her own glory. One month before she dies, the "empire of her hopes" collapses utterly as the establishment into which she has poured her life's energies crumbles into ruin, and she is personally disgraced. She never learns the unhappy truth, however, as her friends, eager to save her from disappointment, conceal or misrepresent the facts. She dies unaware of her disgrace. ${ }^{13}$ Now, it is certainly not wildly implausible to think that Judy's life was made worse (for her) by her disgrace and the ruin of her life's work. Her life would have been better for her if she had not been disgraced and her life's work had not been ruined, even though the ruin had no effect on her mental states.

The examples given by Feinberg and others play on the widespread belief that there is more to the good life than merely having experiences of the right sort. Nozick's famous experience machine case illustrates the plausibility of this intuition. ${ }^{14}$ When it comes to the things that matter to us, most of

${ }^{11}$ Nagel (1970: p. 76).

${ }^{12}$ Feinberg (1984: p. 87).

${ }^{13}$ I borrow this example directly from Feinberg (1984: p. 88). Thomas Carson gives a similar example (2000: p. 77).

14 Nozick (1974: pp. 42-45). 
us do not merely want to experience that things are thus-and-so; we want them to actually be thus-and-so. Most of us do not want merely to be in the mental states typically associated with having a good reputation; we want to actually have a good reputation. And so it seems to many that if someone wants a good reputation, then other things being equal he $i s$ better off getting it, whether getting it affects his mental states or not.

The advantages of a theory like SUDS become obvious when we compare it to what is perhaps its most popular rival: hedonism. Hedonism entails that well-being is determined entirely by how much pleasure and pain we experience. But many of us believe that faring well in life is not simply a matter of enjoying oneself and avoiding unpleasantness. The main strength of a theory like SUDS is its ability to account straightforwardly for this very belief. To see how SUDS shines here, consider the case of Thomas Nagel's deceived businessman. ${ }^{15}$ The man is happy because he believes himself to be getting two things he wants very much: the love of his family and the respect of his colleagues. But his happiness is built on a web of lies. He is surrounded by consummate actors who all merely pretend to love and respect him. In reality, no one loves him and no one respects him. Indeed, his adulterous wife hates him, his children despise him, and his colleagues ridicule him behind his back. Nevertheless, due to the elaborate deception of those around him, the man's life is very pleasant. Hedonism entails that his life is outstandingly good for him and that the deception is not bad for him. Many of us disagree with hedonism's assessment of the case. We think the man would be better off if he were to get genuine love and respect. SUDS can explain this intuition: The problem here is that the man's desires for love and respect are all frustrated, and this harms him; it makes his life worse, even though it does not make his life less pleasant. Hedonism can offer no such easy explanation of what seems wrong with the man's life.

Advocates of SUDS can tell similar stories about experience machines. ${ }^{16}$ Many of us believe that life on such a machine, though perhaps enjoyable, would be intrinsically worse for the one who lives it than a relevantly similar genuine life, off the machine. Hedonists can offer no easy explanation of why the genuine life is better. For hedonists, as well as defenders of other socalled mental state theories of well-being, what matters is how life seems from the inside. And since, from the inside, life on the experience machine seems pretty good, these theories entail that it is. SUDS has a much easier time here. Most of us want to live genuine lives, here in the real world. We want to actually do things, not merely experience simulations. Life on the machine frustrates these desires and so, according to SUDS, it is worse.

And hedonism fares no better when it comes to accounting for things such as posthumous harms and benefits, the harm of libelous rumors spread behind our backs, or the disvalue of frustrated goals that we never become

\footnotetext{
15 Nagel (1970: p. 76).

${ }_{16}$ Nozick (1974: pp. 42-5).
} 
aware of. Since none of these things gives us pain or pleasure, hedonism entails that they can make no difference to the value of a person's life. But of course SUDS can easily handle such cases. According to SUDS, our lives can be made intrinsically better or worse for us after we are dead because we often have desires about what happens once we are gone, and these desires are either satisfied or frustrated. Similar things can be said to explain the disvalue of rumors such as the one discussed by Feinberg and the harm that befalls Judy when she is unknowingly disgraced. These cases involve desire frustration and, according to SUDS, frustrations are intrinsically bad for us, whether or not they cause us pain or we are aware that they occur. ${ }^{17}$

So one main advantage of SUDS is its breadth. Because our desires often range very broadly over the world, the theory can explain why it seems that there must be more to the Good Life than simply enjoying ourselves or having experiences of the right sort. The reason is that most of us do not want merely to have the experiences typically associated with fulfilling our goals, having loving families, good friends or good reputations; we want to actually have these things, as well as the associated experiences and pleasures. But of course the breadth that makes SUDS attractive comes at a price: It commits us to saying that it would be good for Parfit if his desire about the stranger were satisfied and that it would be good for me if people in the $29^{\text {th }}$ century flourish, if the total number of atoms in the universe is prime, and if Napoleon's favorite color was blue. So it appears that SUDS is stuck with the Irrelevant-Desires Problem.

\section{Stating the Irrelevant Desires Problem}

Before proceeding further, it would be helpful if we had a more precise formulation of the problem at hand. What exactly is the objection suggested by Parfit's example and the examples offered by the other philosophers mentioned above? The problem for SUDS seems to revolve around the fact that we sometimes have desires that, in some sense or other, have nothing to do

17 Of course one way to reconcile hedonistic intuitions with SUDS is to show that pleasure is ultimately reducible to desire satisfaction; the result: whenever someone enjoys himself, he necessarily gets some thing, or things, he wants. If such a reduction were available, the defender of SUDS could account for the apparent value of pleasure in two ways. First, he could say that, when someone wants to enjoy himself and does, then his desire for pleasure is satisfied and he thereby benefits by getting something he wants. Second, since pleasure is reducible to desire satisfaction, when a person experiences some pleasure, whether he wants the experience or not, he gets some desire satisfaction anyway since the experience itself entails desire satisfaction.

Reductions of pleasure to satisfaction have been suggested by a number of philosophers. On one reading, Sidgwick suggests such a reduction in the form of what William Alston calls a "motivational theory" of pleasure (Sidgwick (1962: p. 131)), Alston (1967: pp. 344-46)). Richard Brandt, Derek Parfitt, Tom Carson, Chris Heathwood and others have suggested similar views (Brandt (1979: p. 38), Parfit (1984: p. 493), Carson (2000: p. 13), Heathwood (2007)). 
with us. These desires have what we might call remote objects: states of affairs that are, in some obvious sense, beyond the boundaries of what we would ordinarily think of as relevant to the well-being of the person who desires them. Consider some of the desires mentioned above. The object of Parfit's desire about the stranger is this: (S1) the stranger is cured. In itself, this state of affairs has nothing to do with Parfit, let alone his well-being. Consider some of my own desires mentioned above. I want people in the $29^{\text {th }}$ century to flourish, I want the total number of atoms in the universe to be prime, and I want it to be the case that Napoleon's favorite color was blue. The objects of these desires are, respectively: (S2) people in the 29 $9^{\text {th }}$ century flourish, (S3) the total number of atoms in the universe to be prime, and (S4) Napoleon's favorite color was blue. In themselves, these states of affairs have nothing to do with me. They entail nothing about me, that I am this way rather than that, or that I even exist. And we may suppose that their occurrences would have no effect on me whatsoever; none would be a link in any causal chain that ultimately terminates with an event involving me. And so it is no wonder that many would find desires such as these to be irrelevant to how well my life goes.

To make things simple, let us focus on Parfit's example and flesh out some imaginary details of his case so as to emphasize the apparent irrelevance of his desire about the stranger. Parfit himself mentions only one desire he has about the stranger. Let us suppose, perhaps implausibly, that this is the only desire he ever has regarding the stranger. Parfit wants the stranger to be cured, and that is all. Moreover, let us suppose that the desire is rather mild, or at least it is not exceptionally intense as desires go. Let us also suppose that Parfit forms his desire shortly after meeting the stranger and then soon forgets all about it and ceases to have any desires at all about the stranger. So among other things, he has no desire to contribute in any way to the stranger's cure; he has no desire to benefit from the cure, if it were to occur; and he has no desire to ever learn whether or not the stranger is cured. Let us also suppose that the stranger's cure would have no effect on Parfit whatsoever; it would not cause any event involving Parfit. Suppose also that Parfit has no beliefs one way or the other about whether or not the stranger will ever be cured; he simply has no idea. Finally, suppose that if the stranger were eventually cured, the cure would occur long after Parfit has died and ceased to exist. Given all this, we may now formulate the Irrelevant-Desires Problem as a simple argument involving Parfit and his stranger.

Premise One: If SUDS is true, then it would be intrinsically good for Parfit if his desire about the stranger were satisfied, and it would be intrinsically bad for him if it were frustrated.

Premise Two: It would not be intrinsically good for Parfit if his desire about the stranger were satisfied, and it would not be intrinsically bad for him if it were frustrated. 
Therefore, SUDS is false.

Premise one is obviously true. There is no disputing that. And although some philosophers will take it is as self-evident that premise two is true, I think that, if it is true, its truth is certainly not obvious. Indeed I think premise two is false. But before explaining how I think an advocate of SUDS ought to respond to premise two, let me briefly dismiss what I take to be two bad reasons to accept the premise.

\section{Two Bad Rationales for Premise Two}

One bad reason to think that premise two is true revolves around confusion about what SUDS entails. Consider the object of Parfit's desire: (S1) the stranger is cured. As mentioned above, there are several obvious senses in which this state of affairs has nothing at all to do with Parfit. For one thing, it does not entail anything about him; among other things, it does not entail anything about what he feels, or what he thinks, what he does, what happens to him, or even that he exists. Moreover, as a contingent matter, (S1) does not cause anything involving him; that is, the stranger's cure has no effect on any events involving him; his cure does not, for example, trigger a chain of events that ultimately results in his being aware that the stranger is cured or not; it does not cause him to be happy that he has been cured or unhappy that he has not been. So in a couple of obvious senses, (S1) has nothing to do with Parfit; it entails nothing about him and its occurrence does not affect him. But what should we conclude from these facts?

We might conclude that these facts about (S1) themselves entail that the satisfaction of Parfit's desire for (S1) would not be intrinsically good for him. But I think this conclusion is a mistake. As I see it, if a thing is intrinsically good for a person, it has a kind of value that supervenes on its intrinsic properties, and not on the properties, intrinsic or extrinsic, of some distinct thing. And the satisfaction of Parfit's desire for (S1) is something distinct from the occurrence of (S1) itself. According to SUDS, satisfaction of Parfit's desire about the stranger occurs only provided that the following state of affairs occurs:

(P1) Parfit wants the stranger to be cured and the stranger is cured.

Granted, (S1) is entailed by (P1). But since (S1) and (P1) are distinct, (P1) has properties that (S1) lacks. We cannot conclude therefore that the value of (P1) will be determined merely by the properties of (S1). So although (S1) has various properties that might lead us to think that it has nothing to do with Parfit and that perhaps its occurrence would not be intrinsically good for him, the fact that (S1) has these properties does not itself entail that (P1) would not be intrinsically good for Parfit. Moreover, (P1) clearly does have something to do with Parfit. 
Another confused rationale for premise two stems from the idea that, if there is a difference in a person's well-being from one possible world to another, it must be a difference in the state of the person that determines this difference; something about the person must be different from one world to the other. And although the stranger's cure would certainly make a difference in him, it would not in Parfit. Consider my desire about the number of atoms in the universe. Imagine two possible worlds that differ just with respect to the existence of a single atom. In world A, the total number of atoms is prime, whereas in world B the number is not prime. Suppose also that in both worlds I want the total number to be prime; in world A, therefore, my desire is satisfied, and in world B it is frustrated. And if it is intrinsically good for me to get what I want, then I lead a better life in world A than in world B. But the only difference between the two lives is that one takes place in a world with an extra atom. And assuming that the extra atom is not inside me, this is a difference in the world around me, not in me; the difference is entirely external to me. So whether or not my desire is satisfied, nothing about me differs. And so we might conclude that it would not be intrinsically good for me if my desire about the atoms were satisfied, and we might reach a similar conclusion about Parfit's desire regarding the stranger.

Of course the central idea here is that a difference in someone's wellbeing must entail at least some difference in his intrinsic properties. Shelly Kagan discusses this idea at some length in his essay "The Limits of WellBeing." 18 And although he concludes in the end that he has no argument to show the idea to be true, he says that he nevertheless finds it to be "overwhelmingly plausible." I admit there is a whiff of plausibility lingering about, but I would not go so far as to say it is overwhelming. Consider what Kagan says: "Increasing well-being is providing an intrinsic, ultimate benefit to the person; thus, it would have to involve altering the person's intrinsic properties. Since a person just is his body and mind, changes in well-being would have to involve changes in the person's body or mind." Now, although I agree with Kagan that an increase in a person's well-being is intrinsically good for him, I do not think it follows that such an increase entails a change in his intrinsic properties. Let me explain.

I am sympathetic to a conception of intrinsic value according to which a thing's intrinsic value supervenes on its intrinsic properties. So I think that if a person has intrinsic value, this value supervenes on his intrinsic properties. Likewise I think that if a person's life has intrinsic value, its value supervenes on its intrinsic properties. But we need to keep in mind that a person and his life are two distinct things: A person is probably just a physical object, while his life is probably best understood as an event. And, as I see it, assessments of a person's well-being are best understood as assessments of how intrinsically good his life is for him, or how intrinsically good some part of his life is for him. So although I think that a person's well-being does ultimately super-

${ }_{18}$ Kagan (1992: pp. 169-89). 
vene on intrinsic properties, I think the relevant properties are not properties of the person; rather, they are the intrinsic properties of his life. ${ }^{19}$ Let me elaborate.

Imagine a duplicate of yours who exists as the sole inhabitant of his own possible world. You and he are very similar in a number of ways. There is a one-to-one correspondence between your parts and his, and all of the relations that obtain between your parts also obtain between his. But although you and he share exactly the same intrinsic properties, your lives are quite different. You might read philosophy books, ride a motorcycle, build things from wood and teach philosophy courses. Your duplicate, although he shares all your intrinsic properties, does none of these things. You might have children and a house and a car. He has none of these things. You might live in the United States, on earth, in the Milky Way. He lives in none of these places. The differences go on and on. So although you and your duplicate share the same intrinsic character, your lives do not.

But what makes up the intrinsic character of a person's life? I cannot say exactly, but I think the intrinsic character of a person's life in some world is determined, to a large degree, by many of the relational properties that he has in that world. So it is, for instance, an intrinsic property of my life in the actual world that I am now in St. Louis. This of course is not an intrinsic property of mine, but it is an intrinsic property of my life. My being in St. Louis now is part of what makes my life the life it is. A life that is "just like" the one I am now living - a duplicate life, if you will - would involve my being in St. Louis now, or perhaps some counterpart of St. Louis. And my being in St. Louis now is certainly something that a thorough biographer ought not leave out of his story. So it seems to me that this relational property of mine ought to count toward determining the intrinsic character of my life. But what other relational properties of mine should count?

Although I am in no position to give a complete answer to this question, I do think that the cognitive relations I enter into ought to count. It seems to me that if we are to give the full story of a person's life at a world, we ought to mention, for instance, what he believes at that world and whether his beliefs are true or false at that world. And we ought mention what he wants at that world and whether what he wants is the case at that world. These are just the sorts of thing that make a real difference in the character of a person's life. The fact that your duplicate might falsely think he is reading a philosophy paper at the moment is a relevant fact about his life that distinguishes it from your life - a life in which you actually are reading a philosophy paper.

Consider again the example mentioned above involving my desire about the number of atoms in the universe. When we describe the intrinsic character of my life in world A, we ought to include the fact that in that world I

19 Ironically, in a footnote Kagan makes gestures toward the position I am now discussing. See Kagan (1992: p. 182, footnote 7). 
bear the desiring relation to the true state of affairs the number of atoms in the universe is prime. Indeed I think that it may be this relation alone that distinguishes the intrinsic character of my life in world A from that of my life in world B, a world where I do not bear the desiring relation to this true state of affairs. So in world A, my life has an intrinsic property that it lacks in world B. And I can say therefore that the difference in intrinsic value that I think these lives would have for me would indeed be owing to a difference in the intrinsic properties of the two lives. ${ }^{20}$

In the end, therefore, although I agree with Kagan that well-being supervenes on intrinsic properties, I do not agree that the relevant properties are simply those of the person involved; rather, they are the intrinsic properties of his life. Specifically, I think they are the desire satisfactions and frustrations that his life contains. And it seems to me therefore that, although some desire satisfactions do not make a difference in the intrinsic properties of the desirer, this does not entail that these same desire satisfactions are not intrinsically good for him. So even though satisfaction of Parfit's desire about the stranger would not make a difference in his intrinsic properties, I do not think this entails that it would not be intrinsically good for him to get what he wants. And so I think premise two is not supported by the fact that Parfit's intrinsic character would be the same whether or not his desire is satisfied.

\section{Flawed Responses to the Irrelevant-Desires Problem}

Whatever the rationale for premise two, many philosophers consider cases like Parfit's to show that, for any desire-based theory of well-being to get off the ground, it must place at least some restrictions on which desires count so as to rule out the purportedly irrelevant desires. As I see it, two main problems arise when we restrict desires in this way: Either the resulting restricted theory does not successfully avoid the apparent problem of irrelevant desires or it sacrifices too much of what makes desire-based theories of welfare attractive in the first place. While discussing matters closely related to our present topic, James Griffin introduces a restricted desire theory that, as he points out, suffers from the first problem. The theory restricts desires to those that are "fully informed." These are desires that a person would have if he fully appreciated the nature of their objects. Thus, if I fully appreciated what it would be for Napoleon's favorite color to be blue, I might realize that it is silly to want such a thing and consequently cease to have the desire. Accordingly, although I actually have the desire, its satisfaction would not benefit me because it is not fully informed. But as Griffin points out

20 Of course I have skimmed over many difficulties here. There is much more to be said about what a life is and what determines its intrinsic character. I ask the reader to forgive me if I save these difficulties for another time. 
[T] he restriction to informed desires is no help here. I might meet a stranger on a train and, listening to his ambitions, form a strong, informed desire that he succeed, but never hear of him again. And any moderately decent person wants people living in the twenty-second century to be happy and prosperous. And we know that Leonardo had an informed desire that humans fly, which the Wright brothers fulfilled centuries later. Indeed... why would utility not [then] include the desires of the dead? And would that not mean the account had gone badly wrong?21

But of course there are other ways to restrict which desires count. Parfit himself offers a restricted version of desire satisfactionism in the form of his Success Theory, according to which a person's desires are relevant to his well-being only if they are "about his own life." According to this view, Parfit's desire about the stranger would be irrelevant because it is not about his own life; if anything, it is about the stranger's. But it is not clear that the Success Theory will solve the Irrelevant-Desires Problem. To see this, suppose that, after chatting with the stranger for a while, Parfit had not formed a desire that the stranger be cured. Suppose instead that he had formed a desire about his own life, viz., the desire to live a life in a world where the stranger is cured. If this is Parfit's desire, then the Success Theory entails that its satisfaction would indeed be good for him. But surely it is not enough to simply repackage the stranger's cure like this. Anyone who thinks Parfit's original desire was irrelevant must certainly think this new one is too. If SUDS has a problem with irrelevant desires, then surely the Success Theory does also. Of course repackaging Parfit's desire as I have done may strike some as a kind of verbal trick, designed to set up the Success Theory as a straw man. It may be argued that one could flesh out what it is for a desire to be "about a person's life" in such a way so as to make it immune to the kind of irrelevant desires problem that SUDS faces. But as far as I am aware, no plausible "fleshing out" is forthcoming. Moreover, the task of providing a plausible clarification of "being about a person's life" belongs to a defender of the Success Theory, and so I shall not attempt such a clarification here. ${ }^{22}$

Nevertheless, there may be something to the idea that, for a person's desire to count as relevant, its object must at least enter into his life in some important way, even if it need not strictly be "about his life," whatever that might mean. James Griffin gestures in this direction. After pointing out that moving to informed desires will not avoid apparently irrelevant desires, Griffin contrasts his desire about the stranger on the train with another desire he has about his own children. He suggests that, unlike the former desire, the latter enters into his life in a way that would render its satisfaction of some value to him. He writes: "Think of the difference between my desire that the stranger succeed and my desire that my children prosper. I want both, but they enter into my life in different ways. The first desire does not become

${ }^{21}$ Griffin (2002: p. 17).

22 Thanks to Brad Skow here. 
one of my aims. The second desire, on the other hand, is one of my central ends, on the achievement of which the success of my life will turn." ${ }_{23}$

Griffin's words suggest a kind of compromise position we might want to take regarding desire satisfactions such as Parfit's involving the stranger. We might want to distinguish between objects of desire that are central ends and those that we merely want. And we might want to say that satisfactions involving central ends are intrinsically good for us, even if the relevant objects would fail to make any differences in our mental states or intrinsic properties, etc. But we could deny the value of such satisfactions that involve things we merely want. A compromise along these lines would allow us to say, for instance, that satisfaction of Griffin's desire about the stranger would not be intrinsically good for him because the stranger's success is not sufficiently important to him - because it is not one of his central ends. And for similar reasons we could deny the value of satisfying Parfit's desire about the diseased stranger. But the compromise would also allow us to say that satisfaction of Griffin's desire about his children would be intrinsically good for him because his children's prospering is very important to him and is one of his central ends, even though his children's prospering might occur after he no longer exists. And being able to say all these things does have some appeal, so the suggested compromise is not entirely without merit. ${ }^{24}$

But in order for such a compromise to get off the ground, we would of course need to say some more about how to distinguish between objects of desire that are central ends and those that are not. Some things that I want seem correctly described as central ends of mine; others are not. How do we distinguish the central ends from the others? One proposal involves an appeal to facts about intensities. We might suggest that a state of affairs counts as a central end of mine provided that my desire for it is sufficiently intense. Other things I want would not count as central ends of mine because the relevant desires are not sufficiently intense. But even if we are able to make sense of "sufficiently intense" here, this kind of simple appeal to intensities seems problematic. At the moment, I intensely want to keep my job. This is certainly a central end of mine; it is something I hope to achieve. But I also intensely want the earth to continue in its orbit around the sun for the next few days. But the earth continues in its orbit does not seem to be best described as one of my central ends, or indeed as an end of any kind. I do not hope to

${ }^{23}$ Griffin (2002: p. 21).

${ }^{24}$ A different compromise position along similar lines is also suggested, I think, by some things Thomas Scanlon says in his What We Owe To Each Other. Scanlon writes, for example, that "the fulfillment of a person's desire that a distant star should have a certain chemical composition would not, normally, contribute to that person's well-being, but that things might have been different if the person were an astronomer who had devoted his or her life to the development of a theory that would be confirmed or refuted by this evidence." $\mathrm{He}$ then goes on to suggest, I think, that the object of the astronomer's desire, unlike that of the ordinary person who wants the star to be composed of such-and-such, is one of his rational aims, and that "when something becomes one of a person's rational aims it thereby becomes something that affects how his or her life goes." See Scanlon (1998: pp. 120-121). 
achieve anything regarding how the sun moves. Although I have two very intense desires here, one involves a central end of mine and the other does not. We cannot, therefore, distinguish between central ends and mere desires by a simple appeal to intensity such as the one just suggested.

Perhaps we should say that central ends are intensely desired states of affairs in which the person doing the desiring brings something about. So Marke keeps his job counts as a central end of mine because it is something I intensely want and it involves me making something happen. We could then say that, although I intensely want the sun to continue in its orbit, its continuing is not a central end of mine because the earth continues in its orbit does not involve me bringing anything about. It seems to me that characterizing central ends in the way just suggested is rather promising. I think something along these lines is right. The gist of the difference between central ends and things we merely want seems to involve the having of intense desires about what occurs and acting in ways so as to attempt to make them occur. But if we characterize central ends in some way along these lines, where does it get us? Does it help dissipate any of the intuitive stench lingering about the problem of irrelevant desires? Consider again Parfit's desire about the stranger. Because I think that all desire satisfactions are intrinsically good for those who get them, I want to say that it would be intrinsically good for Parfit if the following were to occur:

(P1) Parfit wants the stranger to be cured and the stranger is cured.

Now let's consider the view that (P1) would not be intrinsically good for Parfit because the stranger's cure is not a central end of his. According to this view, being a central end makes a difference. So according to this view, it would be intrinsically good for Parfit if the following were to occur:

(P3) Parfit intensely wants to bring about the stranger's cure and Parfit brings about the stranger's cure.

If the stranger's cure becomes something other than a mere desire of his and becomes something he intensely wants to bring about, then this is alleged to make a difference. It is alleged that, if he now gets what he wants, then a central end of his has been achieved and he gets something intrinsically good for him - namely, the occurrence of (P3). But is there really a relevant difference here? Suppose that after chatting with the stranger, his cure becomes a central end of Parfit's. Suppose Parfit intensely wants to bring it about that the stranger is cured. Suppose he offers him some encouraging words in an attempt to lift his spirits and thereby increase his odds of beating his disease. Suppose that the two part ways and that a few days later, while enrolling in medical school so that he might learn more ways to help the stranger, Parfit chokes on a chicken bone and dies. Suppose that years later, in some distant land, the stranger recalls his brief encounter with Parfit and 
thinks about the encouraging words. Suppose the recollection makes him happy. Suppose his happiness snaps him out of a suicidal depression and causes him to take his medicine. Suppose he is thereby cured. Suppose that had he not recalled Parfit's words he would never have been cured. Has Parfit's central end been achieved?

Well, given that his comforting words are an important link in a causal chain that ultimately results in the stranger's cure, it seems that his end has been achieved. At one time he intensely wanted to bring about the stranger's cure; it was a central end of his. He did some things in an attempt to bring about the stranger's cure; the things he did ultimately worked, albeit after he ceased to exist. Will those who are inclined to deny the value of (P1) be any less inclined to deny the value of (P3)? Perhaps, but I do not know why. If one thinks that the stranger's cure is irrelevant to Parfit's well-being in the case where the cure is merely something he wants, then I do not see why one should think that things would be different in the case where his cure is one of Parfit's central ends. In neither case does Parfit learn of the stranger's cure; in neither case does his cure affect what happens to Parfit or what he does or what he feels or thinks. So why think there is any difference? It seems to me that we ought to make one of two moves here. Either we should say that both (P2) and (P3) are worthless, or we should just bite the bullet and say that both would be intrinsically good for Parfit. Of course it would still be open to us to say that desire satisfactions involving central ends are generally better for us than those involving mere wants. But we could explain this by appeal to the fact that when something is a central end it is generally wanted with greater intensity than when it is merely wanted. Moreover pursuit of a central end will undoubtedly result in the formation of a great many other desires that must be satisfied along the way to its achievement. And all these satisfactions add up to great benefit for the person who achieves one of his central ends.

Another way to restrict desire satisfactionism involves building in some kind of experience requirement. We could say, for instance, that a desire satisfaction is good for its subject only if the subject involved is aware that the desire is satisfied. Wayne Sumner suggests a theory along these lines. ${ }^{25}$ This sort of view would allow us to say that Parfit's desire about the stranger is irrelevant because Parfit will never know one way or the other whether the stranger is cured. But, if we adopt Sumner's experience requirement, we lose the ability to account for cases like that of the deceived businessman. If, as stipulated, the man is unable to distinguish genuine love and respect from the phony variety, then he will never be aware that he is getting the one kind rather than the other. And so, even if the affections around him were genuine, he would not be aware of it; and therefore, according to the view under consideration, he would not be better off if he were to actually get the love and respect he wants. Thus the theory suggested by Sumner simply trades

${ }^{25}$ Sumner (1996: p. 127-28) and Sumner (2000: p. 9). 
one problem for another. It may solve the Irrelevant-Desires problem but at the cost of sacrificing what is best about SUDS: its breadth.

Recently Chris Heathwood has suggested a kind of desire theory that might avoid the Irrelevant-Desires Problem. According to Heathwood's Subjective Desire Satisfactionism (SDS), the fundamental bearers of value are not satisfied and frustrated desires but subjectively satisfied and frustrated desires, i.e., desires that are believed by their subjects to be either satisfied or frustrated. According to SDS, if a person has a desire, he benefits only if, at the same time he has the desire, he believes it is satisfied; and he is made worse off only if he believes it is frustrated. The desire need not actually be satisfied or frustrated. On this view, getting what we want is irrelevant to well-being; what matters is that we believe we are getting it. According to SDS, then, the stranger's fate would be entirely irrelevant to Parfit's wellbeing since, we may suppose, Parfit never comes to believe that the stranger has been cured or that he has not.

Whatever the merits of SDS regarding the Irrelevant-Desires Problem, we should note that it lacks the breadth we are looking for in a genuine desire-theory. SDS is no better than hedonism or Sumner's proposal at handling experience machines or cases such as Nagel's businessman. As stipulated, the businessman wants genuine love and respect, and he believes that he is getting them. According to SDS, therefore, he has nothing further to gain by actually getting what he wants. SDS has the result that there is nothing bad for him about being the pathetic chump that he is. Moreover, given the businessman's ignorance, the puppet masters in his life have no reason whatsoever to feel guilty about how they are treating him; for, if SDS is true, they are not harming him. These are counterintuitive results that no selfrespecting desire theorist should accept. Surely, even though he does not realize he is one, there is something bad for the businessman about being a cuckolded stooge.

Finally, I would like to consider another desire-based theory put forward by Chris Heathwood. Unlike SDS, Heathwood's Actual Desire-Satisfaction Theory (ADST) is a genuine form of desire satisfactionism. And to at least some extent it offers a way to avoid the Irrelevant-Desires Problem. SUDS and ADST are very similar. For present purposes, the relevant difference is that ADST requires concurrence. To explain the concept, Heathwood writes that

in order for a state of affairs to count as a genuine instance of desire satisfaction, the state of affairs desired must obtain at the same time that it is desired to obtain. If I desire fame today but get it tomorrow, when I no longer want it, my desire for fame was not satisfied. A desire of mine is satisfied only if get the thing while I still desire it, and continue to have the desire while I'm getting it. ${ }^{26}$

${ }^{26}$ Heathwood (2005: p. 490). 
Heathwood's restriction of desires to those that are concurrently satisfied or frustrated allows him to say that the satisfaction of Parfit's desire about the stranger is worthless since the cure occurs long after Parfit has ceased to desire it. The restriction does not, however, account for the apparent irrelevance of many other desires. My present desire that the total number of atoms in the universe is prime is either concurrently satisfied or frustrated; my desire about the chemical composition of a distant star is also satisfied or frustrated concurrently. Thus ADST must say that these desires do make a difference to my well-being. But those who believe Parfit's desire to be irrelevant to his well-being would surely also believe that my two desires are irrelevant to mine. The upshot here is that, if the Irrelevant-Desires Problem is a genuine problem, ADST offers only a partial solution.

Moreover, by requiring concurrence, Heathwood has sacrificed too much. He has ruled out a great many desires that any self-respecting desire satisfactionist ought to count as relevant. One advantage of SUDS is that it can easily account for posthumous harms and benefits. If I want my children to flourish after I am dead and gone, they will do so after I have ceased to desire it. According to SUDS this makes no difference; my life would still be made better by the satisfaction of my desire. But ADST would count my desire as irrelevant. I take this as a strike against ADST. In addition to ruling out desires about what happens after I cease to exist, ADST rules out all other desires about what is going on at times distinct from those when I have the desires but still live and desire. Suppose it has come to light that my grandfather's sister was abducted by the Soviet military during World War II; she disappeared, never to be heard from again. I know of the atrocious treatment marauding armies often dish out to women. Suppose I want it to be the case that my grandfather's sister was not beaten, raped and then murdered. Given that her welfare is a concern of mine, we ought to count this desire as relevant to my own. And yet the events that satisfy or frustrate my desire that she not be beaten, raped and tortured occurred at a time when I had no such desires. Indeed, they occurred before I was born. Or suppose I suspect that my family fortune came about through corruption, dirty deals and slave labor. I hope this is not the case. I would rather that my ancestors were not cruel, unscrupulous crooks. Suppose I care a great deal about this, that I have an intense desire that they were honest, good folks. This desire ought to count. My life would be better for me if it were satisfied. Suppose years ago I won the school ping-pong championship, but now I suspect that the tournament was rigged in my favor. I hope this is not the case. I want it to be the case that the tournament was fair. My life would be better if this desire were satisfied. But ADST cannot easily account for the relevance these desires have to my well-being. SUDS can. By counting as relevant desires that are not concurrently satisfied or frustrated, SUDS easily allows us to expand well-being to include our hopes and concerns about the past and future. I 
take this to be an attractive feature of the view, a feature not shared by ADST.27

Requiring concurrence does however have a certain appeal. The appeal is due to the fact that in many cases it would seem strange, if not downright crazy, to say that a person is made better off by satisfying desires he no longer has. Many of us had childhood fantasies about our future professions. We wanted to be truck drivers, firefighters, cowboys or astronauts. It would be ridiculous to say that to make my life better I must now become a cowboy simply because I wanted this as I child. I no longer want to be a cowboy. Or consider a man who for most of his life has intensely wanted to live in Florida when he retires. If at the time of his retirement he has changed his mind and no longer wants to live in Florida, it seems a cruel joke to say that to make his life better he must nevertheless live in Florida simply because doing so would satisfy a desire he once had. Indeed the joke would become even crueler if we force the man to live in Florida when he has not only ceased to want to live there but has also formed an intense desire to live anywhere but Florida. If we restrict desires to those that are concurrently satisfied or frustrated, we need not say that we are made better off by getting what we no longer want.

However, the appeal of concurrence is illusory. The reason it would not now be good for me to suddenly become a cowboy is that since childhood I have not only lost the desire to be a cowboy but I have formed a great many other desires about my life and what I do from day to day, moment to moment. And these other desires would now all be frustrated if I were suddenly to become a cowboy, something I currently do not want to become and want not to become. Similar things can be said about the man who no longer wants to retire to Florida. The cruelty of the joke is explained by the fact that forcing him to live in Florida now would most certainly frustrate at least one desire he currently has, and this would be bad for him. Of course if the man's past desire to live in Florida was sufficiently intense, then SUDS would entail that the man would be overall better off if it were satisfied. Suppose, for example, that for some stretch of time in the past the man wanted to retire to Florida; call this desire " $A$ " and suppose A had an intensity of 10 . But now the man no longer wants to retire to Florida and has instead formed the desire to live elsewhere; call this desire "B" and suppose it has an intensity of 1.

27 I have glossed over some difficulties here, mainly owing to the obscurity of the concept of concurrence. One could argue, for example, that my desire about the ping-pong match is concurrently satisfied or frustrated. After all, I now want it to be the case that the match was fair, and now it either is or is not the case that it was. But if the defender of ADST claims that this desire is concurrently satisfied or frustrated, the same could be said about desires such as Parfit's. If he now wants the stranger to be cured someday, and it is now the case that the stranger is cured someday, then according to ADST Parfit's desire is relevant to his welfare. Thus, to offer even a partial solution to the Irrelevant-Desires Problem, defenders of ADST should not say that desires such as mine about the ping-pong match are concurrently satisfied or frustrated. 
If the man now retires to Florida, then A is satisfied and B is frustrated. Thus if the man were to retire to Florida, the net welfare value would be 9. In this case SUDS has the result that the man would indeed be overall better off if he were to now live in Florida, despite the fact that he now has no desire to live there. At first blush this seems like a counterintuitive result. There appears to be something wrong with how SUDS handles the case. But the appearance is due to the fact that there is something wrong with the case itself, not SUDS. In describing the case, we have focused on just two of the man's desires, A and B. But nobody's life is this simple. Presumably the man has reasons for wanting to live somewhere other than Florida. Perhaps he wants to live in a cooler climate or nearer to his family. Maybe he hates the sight of palm trees and is afraid of alligators. Whatever his reasons, these reasons will be, or will be accompanied by, desires. And many if not all of these desires will be frustrated if he is now forced to live in Florida. Of course if the man's only desires are A and B, then SUDS does "bizarrely" entail that the man would be better off living in Florida. But what is bizarre here is not the result that SUDS gives us, but rather that there would be a man with just these two desires. And it is no strike against SUDS that it gives apparently bizarre results in especially bizarre and improbable cases.

While discussing matters closely related to our present topic, Richard Brandt writes the following:

A convinced skeptic who has rebelled against a religious background wants, most of his life, that no priest be called in when he is about to die. But, when he is on his deathbed he weakens as he feared he would, and asks for a priest. Do we maximizes his welfareDS by summoning a priest, or not?28

I take it that there are several intuitions at work when we consider cases involving past desires such as those of the skeptic and the man who once wanted to live in Florida. When we think about how to do what is best for a person, we naturally focus on his current and future conditions. This is because we are usually concerned with making the current and future parts of his life better: We are not so concerned with the value of his life overall or with the values of earlier parts of his life; we want to improve the part he is currently living and the parts he will live in the future. And, according to SUDS, improving these parts of his life involves satisfying the desires he now has and will have, not those he once had but no longer has. Nevertheless, SUDS does count past desires as relevant. But their relevance to the overall value of a life will typically be mitigated by the fact that merely past desires are usually replaced with a great many other desires that reflect how a person wants things to be as his life moves along. And values of the satisfactions and frustrations of this multitude of new desires will determine how well a person does during the times he has them. Merely past desires are indeed irrelevant

${ }^{28}$ Brandt (1982: p.180). Brandt uses "welfareDS" to signify that he is talking about welfare or well-being as conceived in terms of desire satisfactions and frustrations. 
to how I am doing now, though they do, according to SUDS, play a role in determining the overall value of my life. In Brandt's case, assuming the skeptic's past desire for a priest-free death was sufficiently intense, SUDS does entail that his life would be overall better if he were denied the priest he now wants. But SUDS also entails that the last moments of his life would be better for him if his current desire for a priest were satisfied. After all, he now wants a priest, and it would indeed be cruel to make the last moments of a dying man's life worse for him simply so as to make his life as a whole somewhat better. ${ }^{29}$

\section{Biting the Bullet for SUDS}

The challenge for those sympathetic to a desire-based approach to well-being is to find a way to handle the Irrelevant-Desires Problem without giving up what is best about SUDS, viz., its breadth, its ability to account straightforwardly for the intuition that there is more to the Good Life than how it appears or feels from the inside. The best way to do this, I suggest, is to bite the bullet, embrace the absurdity and simply deny the intuition that some desires are irrelevant to well-being. But to make this position palatable, the defender of SUDS owes us an explanation; he needs to explain away the apparent irrelevance of desires such as Parfit's desire about the stranger and my peculiar desires about Napoleon's favorite color and the number of atoms in the universe.

Let me offer such an explanation. I think it is fair to say that over the course of our lifetimes, moment by moment, each of us will have a huge number (millions? billions?) of often very intense desires. Many of these desires will be occurrent, such as my present desire to drink some beer. Many will be so-called dispositional desires, lurking in the background. Many of our desires will be local desires, typically focused on mundane matters of immediate concern, such as my current desire to scratch my ear. Other desires will be so-called global desires, desires about one's entire life or large segments of one's life. I think my desire to live a life that is on balance more pleasant than painful counts as a global desire. In addition to the occurrent, dispositional, local and global desires, there are certainly other kinds of desires that we all typically have in abundance over the course of a lifetime. Collectively these many desires reveal what we hold important and they determine for each of us, uniquely, what makes life worth living. And I think it is pretty obvious

29 Of course the alternatives to SUDS suggested by Parfit, Griffin, Sumner and Heathwood are but a few of the many possible views one might be drawn to in an effort to avoid socalled irrelevant desires. The possible ways to restrict desire-based theories are indeed many, and it is beyond the scope of this paper to discuss more than a few. Moreover, since my main goal is to argue that moving away from an unrestricted approach is unmotivated, I shall rest content with what I have already said about alternatives to SUDS. 
that a person's desires will tend to cluster around those parts of his life that he takes to be most important. These are the parts of his life that play the biggest role in determining how well his life goes.

Presumably Roger Federer has far more tennis-related desires than I do. This reflects the fact that tennis is far more important to him than it is to me. Tennis is an important part of his life. And whether or not his many tennisrelated desires are satisfied will in part determine, I think, how well his life goes. Tennis is not so important to me and so my desires tend to cluster around different things, like watching TV and drinking beer. But when it comes to the overall desiderative contents of our lives, I think that, in some obvious respects, Federer and I are probably more similar than different. Surely the overwhelming majority of our desires, and the most intense among them, are exclusively parochial. They concern our own lives, matters directly involving our jobs and our families and friends, and from moment to moment they include myriad desires about our own sensory experiences and what is going on immediately around us. I want to stop feeling that itchiness on my ear, I want to continue breathing, I want my heart to keep pumping, and I want the room to be a little less stuffy, et cetera, et cetera. No doubt, as we speak, Federer has similar, mundane and parochial desires. Maybe he is in the middle of a match and perhaps he wants the string tension in his racket to be a bit tighter, maybe he wants that sun to stop shining in his eyes whenever he serves, and certainly he would like to keep breathing, et cetera, et cetera.

But of course Federer and I are not special cases. When it comes to what they want, most people, most of the time, are almost exclusively focused on themselves. These self-focused desires form the dense core of a sphere of desires that extend outward, usually to include desires about things less directly related to our own moment-to-moment existence. These include desires about our friends, families and careers. Sometimes the sphere of desires will extend to include desires about strangers. And sometimes it will extend even further, including desires with even more remote objects, like desires about the number of atoms in the universe.

Now if we imagine ourselves in Parfit's place, and we imagine ourselves with a desire like his about some diseased stranger, most of us will probably conclude that the stranger's cure, whether it happens or not, would have no bearing at all on our own well-being. Perhaps his, but not ours. I think what is going on when we reach such a conclusion is something like this. We realize that, in the grand scheme of our own lives, the stranger and his problems just are not very important to us. The stranger is after all just a stranger; we spend a few minutes with him, and then he is gone. And because he plays such a small part in our lives, our concern for him takes the form of just one measly desire, the desire that he be cured. When compared with our many other concerns, revealed by all our self-focused, parochial desires about our own lives, and our own subjective experiences, our concern for the stranger 
pales in significance. At best, our solitary desire about him is near the remote edge of the sphere of desires that determine our most significant interests.

The sheer quantity and intensity of all the desires we have that are not about the stranger indicate that we care far more about ourselves, our own experiences, and things close to us than we do about the stranger. And since the satisfaction of our lone desire about the stranger would make no difference whatsoever to whether or not we get any of the many things we really care about (wining the French Open again, a beer, an itch-free ear, a loving family, pleasure, a lifetime of happiness) we are apt to conclude that his cure would really make no difference at all to our well-being. This is a natural conclusion to reach, but I think it is a mistake. At most, I think we are entitled to conclude that the stranger's cure would have just a negligible relevance to our overall well-being; after all, our desire about him is probably rather mild and just one amongst a vast universe of far more intense desires. Moreover, if it is a merely past desire, it has no relevance to our current wellbeing. That we should conclude his cure would have some relevance rather than none is, I think, justified given that we do after all care whether or not he is cured; his cure is a concern of ours, though I grant a very minor one. If it were not, then we would not even have just the one desire. ${ }^{30}$

Mark Lukas

Longwood University

Department of History, Political Science and Philosophy

lukasme@,longwood.edu

${ }^{30}$ I thank Bruce Aune, Phil Bricker, Ben Bradley, Roger Crisp, Fred Feldman, Chris Heathwood, Eric Moore, Luke Robinson, Scott Senn, Brad Skow, David Waller, Susan L. Wampler and the audiences at the Rocky Mountain Ethics Congress, the Mid-South Philosophy Conference and the John Stuart Mill Bicentennial Conference. Finally, I am very grateful to my anonymous referee; the feedback offered led to many substantial improvements. 


\section{References}

Adams, Robert. 1999. Finite and Infinite Goods. Oxford: Oxford University Press.

Alston, William. 1967. "Pleasure." In Edwards, Paul (ed.), The Encyclopedia of Philosophy, Vol. 6: 341-347. New York: Macmillan Publishing Co. \& The Free Press.

Bradley, Ben. 2007. "A Paradox for Some Theories of Welfare.” Philosophical Studies 133: 4553.

Brandt, Richard. 1979. A Theory of the Good and the Right. Oxford: Clarendon. 1982. "Two Concepts of Utility." In Miller \& Williams (eds.), The Limits of Utilitarianism: 169-185. Minneapolis: University of Minnesota Press. 1996. Facts, V alues, and Morality. Cambridge: Cambridge University Press.

Carson, Thomas. 2000. Value and the Good Life. Notre Dame, Ind.: University of Notre Dame Press.

Feinberg, Joel. 1984. Harm to Others. Oxford: Oxford University Press.

Feldman, Fred. 2004. Pleasure and the Good Life: Concerning the Nature, Varieties, and Plausibility of Hedonism. Oxford: Oxford University Press.

Griffin, James. 2002. Well-Being: Its Meaning, Measurement, and Moral Importance. Oxford: The Clarendon Press.

Heathwood, Chris. 2005. "The Problem of Defective Desires." Australasian Journal of Philosophy 83: 487-504.

2006. "Desire Satisfactionism and Hedonism." Philosophical Studies 128: 539-63.

2007. "The Reduction of Sensory Pleasure to Desire." Philosophical Studies 133: 23-44.

Hooker, Brad. 1993. "A Breakthrough in the Desire Theory of Welfare." In Heil, John (ed.), Rationality, Morality, and Self-Interest: Essays Honoring Mark Carl Overvold: 205-213. Lanham, Md.: Rowman \& Littlefield.

Kagan, Shelly. 1992. "The Limits of Well-Being." In Paul \& Paul (eds.), The Good Life and the Human Good: 169-189. Cambridge: Cambridge University Press. 1998. Normative Ethics. Boulder: Westview Press.

Kraut, Richard. (1997). "Desire and the Human Good." In Carson \& Moser (eds.), Morality and The Good Life: 164-76. Oxford: Oxford University Press.

Murphy, Mark. 1999. “The Simple Desire-Fulfillment Theory.” Nous 33:2: 247-72.

Nagel, Thomas. 1970. "Death.” Nous. Vol. 4, No. 1: 73-80.

Noggle, Robert. 1999. "Integrity, the Self, and Desire-Based Accounts of The Good." Philosophical Studies 96: 303-31.

Nozick, Robert. 1974. Anarchy, State and Utopia. New York: Basic Books.

Overvold, Mark. 1982. "Self-Interest and Getting What You Want." In Miller \& Williams (eds.), The Limits of Utilitarianism: 186-194. Minneapolis: University of Minnesota Press.

Parfit, Derek. 1984. Reasons and Persons. Oxford: Oxford University Press.

Scanlon, Thomas. 1993. "Value, Desire, and Quality of Life." In Nussbaum \& Sen (eds.), The Quality of Life: 185-200. Oxford: Clarendon Press.

1996. "The Status of Well-Being." University of Utah website: http://www.tannerlectures.utah.edu/rstu.html (last visited January 18, 2005). 1998. What We Owe to Each Other. Cambridge: The Belknap Press of Harvard University Press.

Sen, Amartya. 1993. "Capability and Well-being." In Nussbaum \& Sen (eds.), The Quality of Life: 30-53. Oxford: Clarendon Press.

Sidgwick, Henry. 1962. The Methods of Ethics. London: Macmillan \& Company LTD.

Sobel, David. 1994. "Full Information Accounts of Well-Being." Ethics, 104: 784-810.

Sumner, L. W. 1996. Welfare, Happiness, and Ethics. Oxford: Clarendon. 2000. "Something in Between." In Crisp \& Hooker (eds.), Well-Being and Morality: Essays in Honor of James Griffin: 1-19. Oxford: Clarendon Press.

Schwartz, Thomas. 1982. "Human Welfare: what it is not." In Miller \& Williams (eds.), The Limits of Utilitarianism: 195-206. Minneapolis: University of Minnesota Press. 